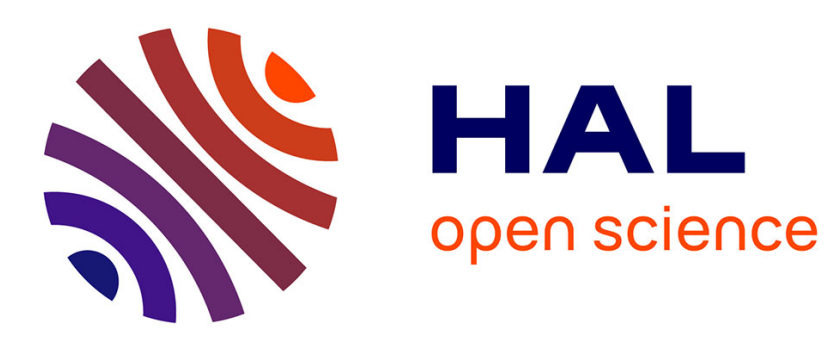

\title{
A Study of Near-Tip Local Parameters for Stable Crack Growth with a 3D FE-Analysis
}

\author{
O. Kolednik, G. Shan, W. Yan, F. Fischer
}

\section{To cite this version:}

O. Kolednik, G. Shan, W. Yan, F. Fischer. A Study of Near-Tip Local Parameters for Stable Crack Growth with a 3D FE-Analysis. Journal de Physique IV Proceedings, 1996, 06 (C6), pp.C6-521-C6527. 10.1051/jp4:1996652 . jpa-00254485

\section{HAL Id: jpa-00254485 https://hal.science/jpa-00254485}

Submitted on 1 Jan 1996

HAL is a multi-disciplinary open access archive for the deposit and dissemination of scientific research documents, whether they are published or not. The documents may come from teaching and research institutions in France or abroad, or from public or private research centers.
L'archive ouverte pluridisciplinaire HAL, est destinée au dépôt et à la diffusion de documents scientifiques de niveau recherche, publiés ou non, émanant des établissements d'enseignement et de recherche français ou étrangers, des laboratoires publics ou privés. 


\title{
A Study of Near-Tip Local Parameters for Stable Crack Growth with a 3D FE-Analysis
}

\author{
O. Kolednik, G.X. Shan*,1, W.Y. Yan* and F.D. Fischer**
}

Erich-Schmid-Institut für Festkörperphysik der Österreichischen, Akademie der Wissenschaften, Jahnstr. 12, 8700 Leoben, Austria

* Christian-Doppler-Laboratorium für Mikromechanik der Werkstoffe, 8700 Leoben, Austria

** Christian-Doppler-Laboratorium für Mikromechanik der Werkstoffe und Institut für Mechanik der Montanuniversität Leoben, 8700 Leoben, Austria

\begin{abstract}
A 3D-FEM simulation of a fracture mechanics test is presented where the crack extension, $\Delta a$, is controlled by local $\Delta a$ vs. load line displacement curves measured on different locations along the crack front. These data originate from an extensive multispecimen $J_{I C}$-test. The results of the $3 \mathrm{D}$-analysis fit excellently to the experimental data and to the results of a modified two-layer model used in preceding studies. The current $3 \mathrm{D}$-analysis supports the assumption that (after a short transition region) the local crack tip opening angle remains constant during growth.
\end{abstract}

\section{INTRODUCTION}

In previous work we developed a two-layer model to simulate numerically crack extension in plain sided fracture mechanics specimens $[1,2]$. A plane strain layer should reflect the behaviour near the specimen midsection and a plane stress layer that of the two near side-surface regions. The crack growth resistance curves were determined by analysing fracture initiation and crack growth in the two layers separately controlled by constant critical values of the crack tip opening displacement, $\mathrm{COD}$, and the crack tip opening angle, $\mathrm{CTOA}_{c}$.

The two-layer model has been applied successfully to simulate fracture mechanics tests numerically $[2,3]$ and to investigate effects of geometry and size on the crack growth resistance curves [4-7]. A recent review of the results is given in [8].

Nevertheless, we have always been aware of the fact that this model is only a simplification of the reality which, e.g., cannot be applied for structures with a more complicated geometry. Here a 3D-analysis is inevitable. Hardly any successful 3D-simulations of crack growth with sufficiently fine meshes can be found in literature. This is not only due to the high computing costs but also because of the lack of appropriate fracture criteria to control the varying crack growth rates along the crack front.

In the current study we tried to overcome the latter difficulty. The new 3D-procedure is introduced in the following section.

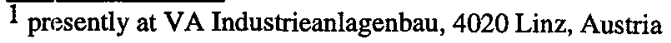




\section{A 3D-FE ANALYSIS OF STABLE CRACK GROWTH}

The idea is to use experimentally measured curves of the local crack extension, $\Delta a$, vs. the load line displacement, $v_{\mathrm{LL}}$, as the input data for the $3 \mathrm{D}$-analysis. The data originate from an extensive multi-specimen $J_{I C}$-test [9]. The specimens were Compact Tension (CT-) specimens with a thickness $B=25 \mathrm{~mm}$, a width $W=50 \mathrm{~mm}$ and an initial crack length $a_{0} \approx 27 \mathrm{~mm}$. The material was an annealed mild steel St37 exhibiting a yield strength of about $\sigma_{y}=270 \mathrm{MPa}$, an ultimate tensile strength $\sigma_{u}=426 \mathrm{MPa}$ and a Young's modulus $E=200 \mathrm{GPa}$. The measured true stress vs. true strain curve from a tensile test is implemented point by point (and linearly extrapolated for very high strains). It should be mentioned that the stress strain curve of the annealed mild steel exhibits a sharp yield point and a Lüders strain. (For the analysis the stress was held constant within the Lüders strain region.) The exact shape of the experimental stress strain curves depends on the cooling conditions after the annealing, and this is the reason why the scatter band of the experimental load- $v_{\mathrm{LL}}$ and $J-\Delta a$-curves is rather wide.

In the $J_{I C}$-test $\Delta a$ was measured on 9 equidistant positions along the crack front (as prescribed by the Standard Procedures for $J_{I C}$-Testing $[10,11]$ ). As only a quarter of the specimen is modelled the $\Delta a$-data in positions symmetrically to the midsection are averaged. At the remaining five positions between $z=0$ (midsection) and $z=12.5 \mathrm{~mm}$ (side surface) the measured data are fitted by polynomial functions, see Fig. 1. The polynomial functions $\Delta a=\Delta a\left(v_{\mathrm{LL}}\right)$ allow to control the local fracture initiation and crack extension.

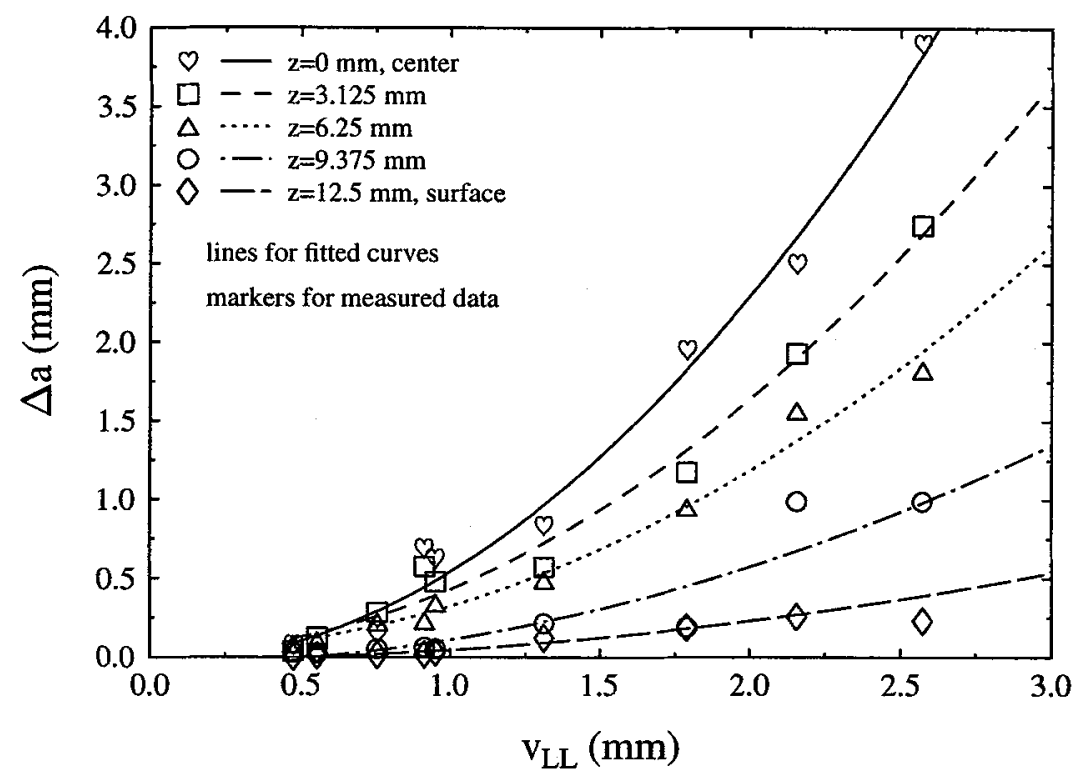

Figure 1: The local crack extension versus load line displacement $\left(\Delta a-v_{L L^{-}}\right)$data from a $J_{I C}$-multi specimen test which were measured at different positions $z$ along the crack front serve as the input data for the 3D-analysis

The crack extension is modelled in steps of $0.1 \mathrm{~mm}$. Each local $\Delta a$ vs. $v_{\mathrm{LL}}$-curve is intersected at $\Delta a=0.1 \mathrm{~mm}$ to determine the critical $v_{\mathrm{LL}}$-values where the first step of crack extension, i.e. the local fracture initiation, has to be made. The same is repeated for $\Delta a=0.2,0.3, \ldots \mathrm{mm}$. The maximum crack extension in the specimen centre amounts about $3 \mathrm{~mm}$. The corresponding average crack extension at this loading stage is about $1.5 \mathrm{~mm}$. 
The finite element analysis is performed with ABAQUS [12]. Four layers of 3D-elements are used, each $3.125 \mathrm{~mm}$ thick. The elements near the crack plane have a quadratic cross section of $0.1 \mathrm{~mm}$ length. The FE-mesh of the specimen is shown in Fig. 2.

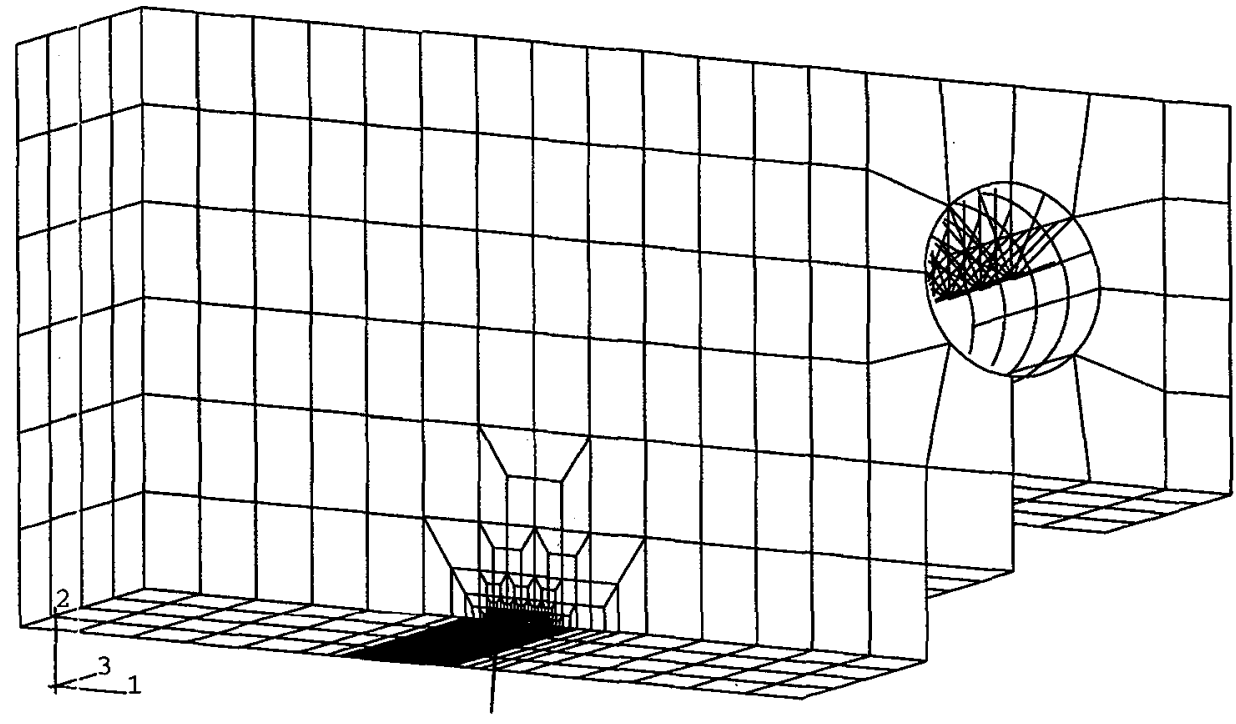

Figure 2: The FE-mesh of a quarter of the Compact Tension specimen used for the 3D-analysis of crack growth

The loading process is controlled by prescribing the load line displacement, $v_{\mathrm{LL}}$. The local crack extension is modelled by the node release technique without node shifting. During the local crack extension, which is performed by releasing the corner node and the two adjacent mid nodes, $v_{L L}$ is held constant. An example is presented in Fig. 3: At the value of the load line displacement where the local $\Delta a$ vs. $v_{\mathrm{LL}}$-curve for $z=3.125 \mathrm{~mm}$ reaches $\Delta a=0.2 \mathrm{~mm}$ a local crack extension in Layer 2 from $\Delta a=0.1$ to $\Delta a=0.2$ is made.

\section{3. 'THE MODIFIED TWO-LAYER MODEL}

As described above, constant $\mathrm{CTOA}_{c}$-values were used in the earlier studies with the two-layer model [2]- [8]. The transition region with decreasing $\mathrm{CTOA}_{c}$-values which appears after initiation of crack growth (see Fig. 6) was neglected. However, to check the principle validity of such a twolayer model, identical criteria for crack growth should be used for the 3D-analysis and the two layer model. Therefore, in the current study the crack extension in the two layers is controlled by the local $\Delta a$ vs. $v_{\mathrm{LL}}$-curves for $z=0$ (for the plane strain layer) and for $z=12.5 \mathrm{~mm}$ (for the plane stress layer) of Fig. 1. Crack growth in the two layers is analysed independently.

The relative thicknesses of the two layers were determined such that (for a stationary crack) the two-layer composite exhibits the same load-displacement curve as a real specimen or as a 3D-analysis. The procedure is described extensively in $[1,2,4]$. 
- unreleased nodes
$\times$ released nodes
0 currently released nodes

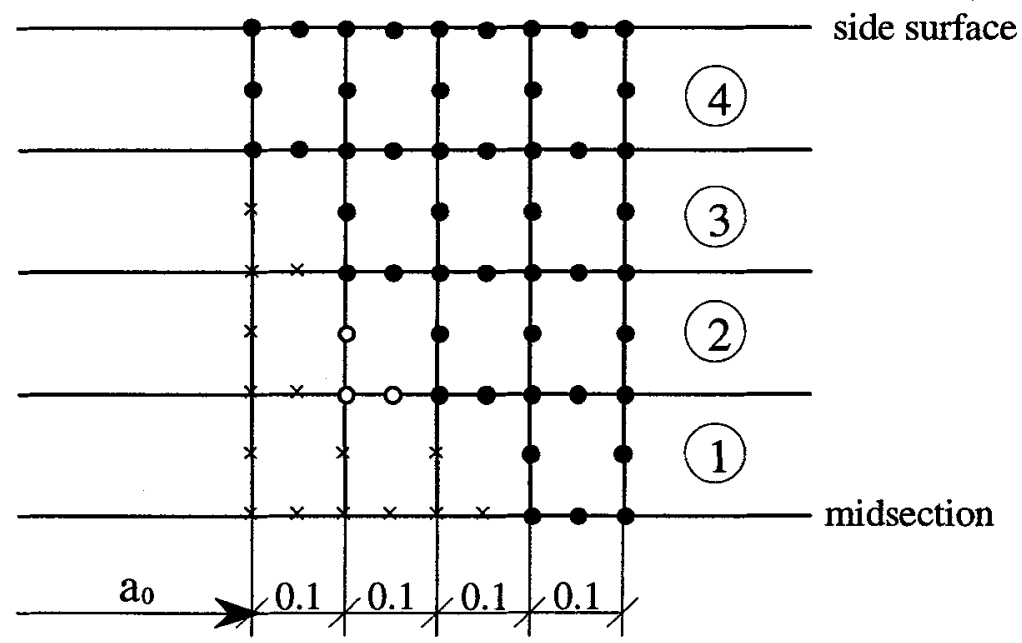

Figure 3: Local crack extension in Layer 2

\section{RESULTS AND DISCUSSION}

In Fig. 4 the resulting load vs. displacement curve of the new 3D-analysis is presented, together with the result of the modified two-layer model and the experimental curves. As in the experiments the initial crack lengths varied a little bit, the load, $P$, is plotted related by the limit load,

$$
P_{L}=\frac{B b_{0}^{2} \sigma_{y}}{2 W+a_{0}}
$$

$b_{0}$ is the initial ligament length, $b_{0}=W-a_{0}=23 \mathrm{~mm}$. The results of the new $3 \mathrm{D}$-analysis and the modified two-layer model almost coincide, and both curves lie near the upper boundary of the experimental curves.

The $J$-integral vs. crack extension curves are collected in Fig. 5. Again, the scatter of the experimental results is rather large and the curves of the $3 \mathrm{D}$ - and the modified two-layer analyses lie well within this scatterband. Earlier plane strain analyses [8] revealed that for the low strength material considered (and for the given specimen size), the load reaches the plastic limit load before or at the point of fracture initiation. The load vs. displacement behaviour of the specimen is not strongly influenced by the crack extension, contrarily to the behaviour of a high strength material. It was found that when applying the two-layer model for a stationary crack the division of the specimen into the plane strain and the plane stress layer remains nearly unchanged after the plastic limit load has been reached. So the "correct" division of the specimen into the plane strain and the plane stress layer will not change dramatically during crack extension, too, and the new 3D-analysis and the result of the modified two-layer model yield nearly coincident curves.

Fig. 6 shows the development of the local CTOD with increasing crack extension. The CTODvalues are taken one element size behind the advancing tip just in the moment before a local crack extension occurs, i.e. at the critical $v_{\mathrm{LL}}$-values. Within a transition region all local CTOD-values decrease with increasing crack extension but after some amount of crack growth CTOD remains constant. As expected, this local steady-state CTOD is lowest in the specimen midsection $(z=0)$ and increases when approaching the side surfaces $(z=12.5 \mathrm{~mm})$. The size of the midsection steady- 


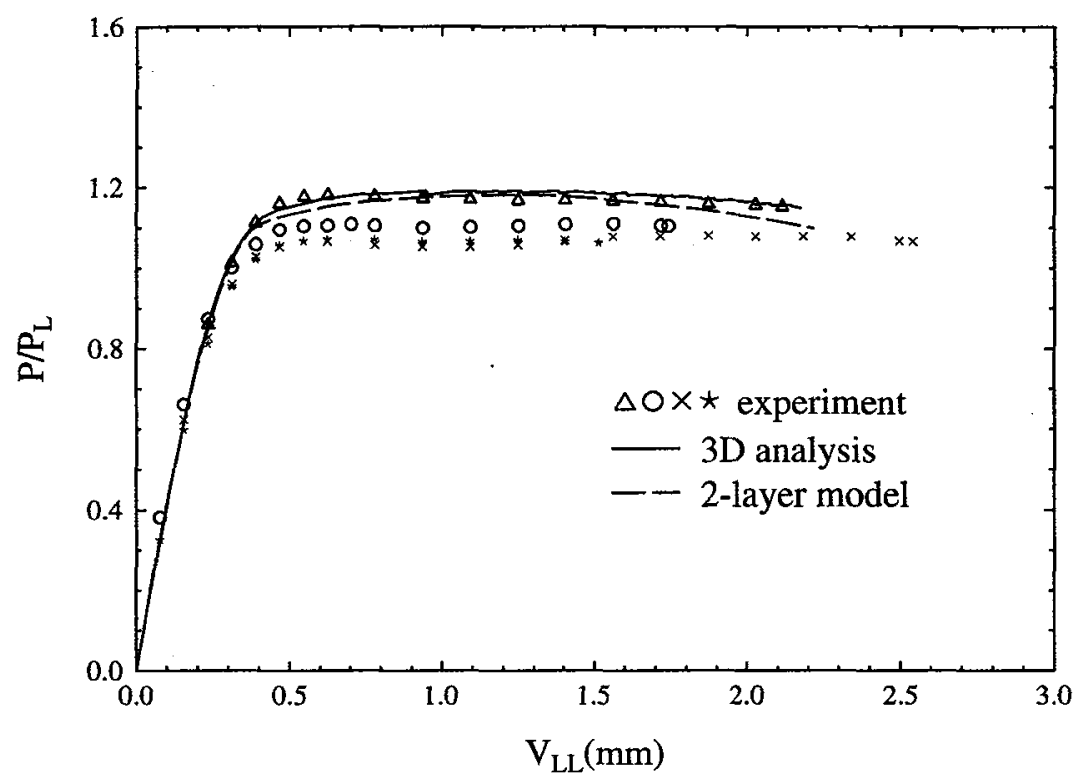

Figure 4: Load divided by the plastic limit load versus load line displacement $\left(P / P_{\mathrm{L}^{-}} v_{\mathrm{LL}^{-}}\right)$curves of the new $3 \mathrm{D}$-analysis and the modified two-layer model together with experimental data

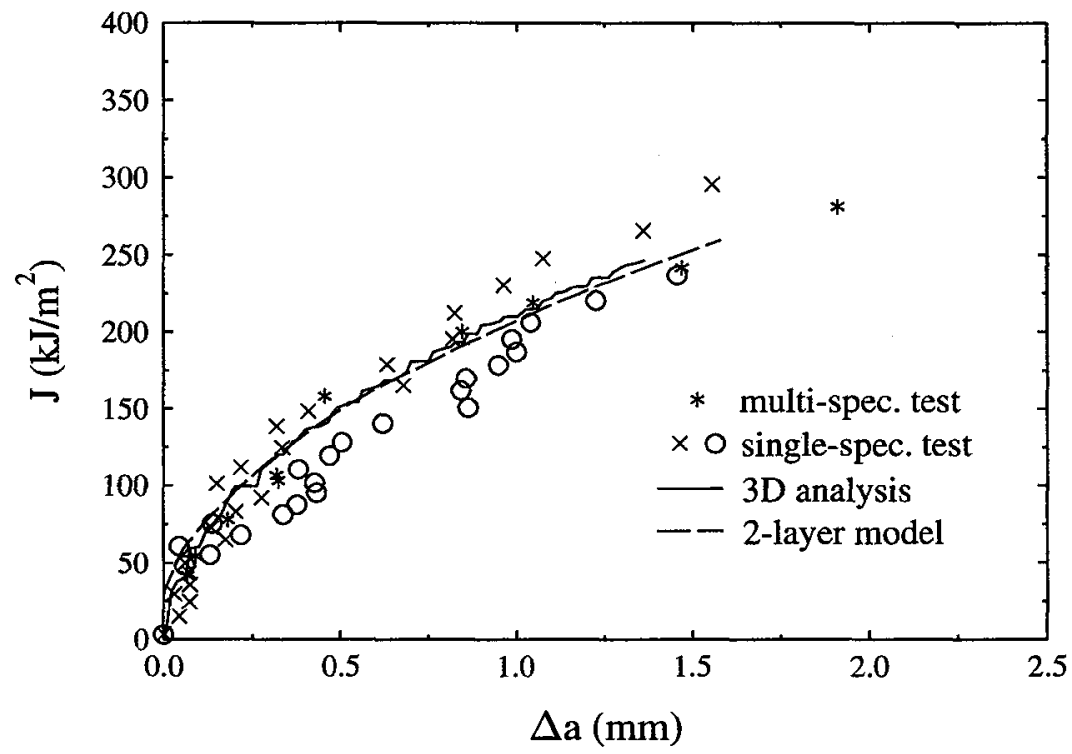

Figure 5: Resulting $J$-integral versus crack extension $(J-\Delta a-)$ curves of the new $3 D$-analysis and the modified two-layer model together with experimental data 


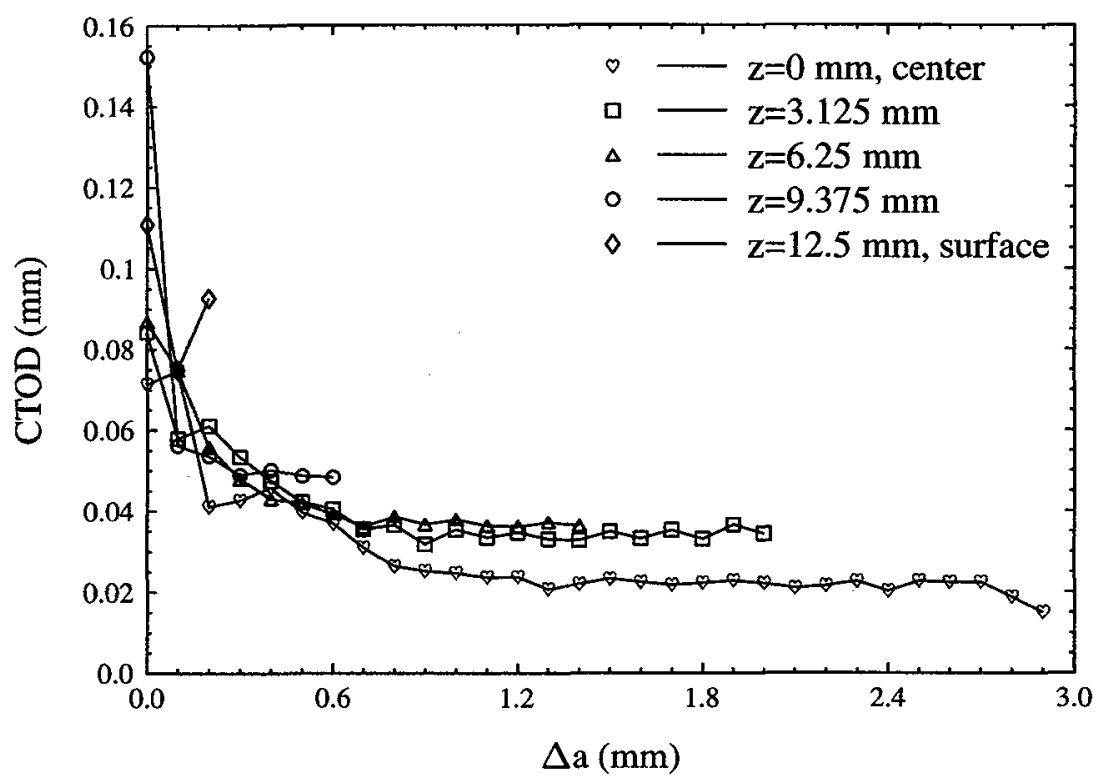

Figure 6: The development of the local crack tip opening displacement, CTOD, at the advancing tip during crack extension, $\Delta a$, for different positions $z$ along the crack front

state CTOD $(\approx 25 \mu \mathrm{m})$ corresponds quite well to the critical midsection CTOD $(=26.6 \mu \mathrm{m})$ of the earlier two-layer analyses [5,8]. It is a little bit surprising that even for $z=3.125 \mathrm{~mm}$ the steady-state CTOD, or $\mathrm{CTOA}_{c}$, is appreciably larger than in the midsection. Taken in terms of $\Delta a$ the width of the transition region decreases from the midsection to the side surface.

The CTOD-values for $\Delta a=0$ correspond to the local COD $_{i}$-values ${ }^{1}$. E.g., for the midsection $\operatorname{COD}_{i}(z=0) \approx 73 \mu \mathrm{m}$ which is exactly equal to the plane strain value used in the earlier two layer analyses $[5,8]$. At the side surface the value does not fit so well. The reason why $\operatorname{COD}_{i}(z=12.5)$ is smaller than $\operatorname{COD}_{i}(z=9.375)$ is not yet fully understood. But it might be ascribed to the fact that the width of the outer finite element layer has been made too large. E.g., the analysis yields too small values of the lateral contraction of the specimen compared to the experiment.

The current $3 \mathrm{D}$-analysis supports the assumption of a constant local CTOA $_{c}$ during crack extension used in our earlier studies with the two-layer model. This will be true as long as the local in-plane and out-of-plane constraint situation does not change appreciably during crack growth [13].

\section{SUMMARY AND CONCLUSIONS}

1. A 3D-simulation of crack growth in a compact tension specimen made of a mild steel has been conducted where the crack extension, $\Delta a$, is controlled by local $\Delta a$ vs. displacement curves.

2. The 3D-analyis fits excellently to the experimental load vs. displacement and $J$-integral vs. $\Delta a$-curves and nearly coincides to the results of a modified two-layer model presented in this study.

3. The local CTOD vs. $\Delta a$-curves reveal a short transition region with decreasing CTOA $_{c}$-values, followed by a region of steady-state CTOD or CTOA $_{c}$-values. The steady-state CTOA $_{c}$-values increase from midsection to side surface.

\footnotetext{
${ }^{3}$ Note that for various values of $z$ fracture initiation happens at different $v_{L_{L}}$-values.
} 
4. In the current analysis the specimen is modelled by four equidistant finite element layers over half the thickness. The results show that the thickness of the outer layer is too large to model correctly, e.g., the lateral contraction of the specimen or the critical COD at fracture initiation.

\section{References}

[1] Shan G.X., Kolednik O., Stüwe H.P. and Fischer F.D., Engng Fracture Mech. 41 (1992) 625-633.

[2] Shan G.X., Kolednik O., Fischer F.D. and Stüwe H.P., Engng Fracture Mech. 45 (1993) 99-106.

[3] Shan G.X., Kolednik O. and Fischer F.D., Localized Damage III, Computer Aided Assessment and Control (Computational Mechanics Publications, Boston, 1994) pp.399-406.

[4] Shan G.X., Kolednik O. and Fischer F.D., Int. J. Fracture 66 (1994) 173-187.

[5] Shan G.X., Kolednik O. and Fischer F.D., Constraint Effects in Fracture: Theory and Applications, ASTM STP 1244 (ASTM, Philadelphia, 1995) pp.71-87.

[6] Kolednik O., Shan G.X. and Fischer F.D., IUTAM-Symposium on Size Scale Effects in the Failure Mechanisms of Materials and Structures (E \& FN Spon, London, 1995) pp.495-507.

[7] Shan G.X., Kolednik O. and Fischer F.D., Int. J. Fracture, in press.

[8] Kolednik O., Shan G.X. and Fischer F.D., Fatigue and Fracture Mechanics: 27th Volume, ASTM STP 1280 (ASTM, Philadelphia, 1996) in press.

[9] Kolednik O. and Stüwe H.P., Engng Fracture Mech. 24 (1986) 277-290.

[10] ASTM E1152-87, Standard test method for determining $J$-R-curves. Annual Book of ASTMStandards Vol.03.01 (ASTM, Philadelphia, 1993).

[11] ESIS P2-92, ESIS procedure for determining the fracture behaviour of materials (ESIS, Delft, The Netherlands, 1992).

[12] Hibbit H.D., Karlsson B.I. and Sorensen E.P., ABAQUS User's Manual, Version 4.7., 1988.

[13] Kolednik O., Shan G.X. and Fischer F.D., IUTAM-Symposium on Nonlinear Analysis of Fracture (Kluwer Academic Publishers, Dordrecht, The Netherlands, 1995) in press. 